\title{
$\cdot \nabla$ \\ IJCRR \\ Axial length and Refractive Status of Adults in South Western Nigeria
}

Section: Healthcare

Sci. Journal Impact

Factor: 5.385 (2017)

ICV: 71.54 (2015)

\section{Onabolu Oluwatoni ${ }^{1}$, Jagun Omodele ${ }^{2}$, Ajibode Haruna ${ }^{3}$, Fakolujo Victoria ${ }^{4}$}

'Department of Ophthalmology, Olabisi Onabanjo University Teaching Hospital. Sagamu. Ogun State, Nigeria; ${ }^{2}$ Ophthalmology Unit, Babcock University Teaching Hospital, Ilishan-Remo, Ogun State, Nigeria; ${ }^{3}$ Department of Ophthalmology, OOUTH, Sagamu, Ogun State, Nigeria; ${ }^{4}$ Ancilla Catholic Hospital Eye Centre, Agege, Lagos State, Nigeria.

\section{ABSTRACT}

Background: The axial length of the eye is the distance between the centre of the cornea and the retina. This is one of the determinants of the refractive state of the eye and a knowledge of this is useful in intraocular lens power calculation during cataract surgery. The main objective of this study is to report the normal distribution of axial length and refractive. Status of the adult eye in South Western Nigeria.

Methods: A multistage cluster random sampling technique was used to select participants. In Sagamu Local Government, who had axial length determination, automated refraction and biometry done.

Results: Three hundred and two adults participated in this study. There were $121(40 \%)$ males. In $83 \%$ the axial length ranged between $22 \mathrm{~mm}$ and $24.5 \mathrm{~mm}$. The mean axial length was $23.31 \pm 0.91 \mathrm{~mm}$ with males being significantly longer [p<0.001] and a progressive increase noted between 18 to 40 years of age. There were 213 participants with refractive errors, $55 \%$ were hyperopic while $16 \%$ were myopic. Axial length also showed a statistically significant but weak [R2 $=0.07]$ inverse correlation with the refractive states of the eye.

Conclusion: Axial length of the adult eye in South Western Nigeria was found to be inversely related to; but not an independently strong determinant of the refractive state of the eye..

Key Words: Axial length, Refractive, Nigerians

\section{INTRODUCTION}

At birth, the average axial length [AL] of the eye is $17.0 \mathrm{~mm}$ and this increases with age following a triphasic pattern ${ }^{1-3 .}$ The first phase of increase occurs within the first two years of life with an average growth of $4.4 \mathrm{~mm}$, the second increase of about $1.5 \mathrm{~mm}$ occurs between ages 2 to 6 years, while the last phase extends into adulthood with another $1.0 \mathrm{~mm}$, resulting in an average adult eye of $23.9 \mathrm{~mm}^{1,4}$.

The eye is able to form clear images by the process of refraction where light rays from infinity enter the eye and are bent mainly by the cornea and lens to form a clear image on the retina ${ }^{4}$.

The average refractive power of the adult human eye is +60.0 $\mathrm{D}^{5}$ and axial errors of refraction [myopia and hyperopia] are major causes of visual impairment and are correctable by lenses ${ }^{4}$.
Previous studies in different races have documented average AL diameters ranging from $22.61 \mathrm{~mm}$ to $23.57 \mathrm{~mm} .^{6-11}$ These values are higher in individuals with myopia as compared to emmetropia and hypermetropia. ${ }^{6-10}$

AL has also been shown to accounts for variability in the refractive state of the eye in different studies ${ }^{7,9,12}$

The purpose of this population based study is to determine the relationship between axial length and refractive status of normal adult eyes in South Western Nigeria as a possible predictive indices of the refraction of the eye.

Materials and Methods: The study area was Sagamu Local Government Area [SLGA] which is one of the twenty local government areas in Ogun state located in the South western region of Nigeria. SLGA has a population of 253,421 people with $51 \%$ females and is divided into two health districts -

Corresponding Author:

Jagun Omodele [FMCOph], Ophthalmology Unit, Babcock University Teaching Hospital, Ilishan-Remo, Ogun State, Nigeria. Ph: +234-8023184198; Email: omodelly@yahoo.com

ISSN: 2231-2196 (Print)

Received: 01.11 .2018
ISSN: $0975-5241$ (Online)

Revised: 18.11 .2018
Accepted: 12.12 .2018 
Makun and Offin with a population of 74,900 and 178,521 respectively ${ }^{14}$.

For this study, a minimum sample size of 300 adults was calculated using the Leslie Kish formula. Study participants were selected using a multistage random sampling technique such that 2 clusters of 50 subjects each were chosen from Makun and 4 clusters from Offin.

The inclusion criteria were, adults 18 years and above, with no known ocular pathology apart from cataracts and refractive error. Exclusion criteria were denial of consent, a history of extraocular or intraocular surgery and history of severe ocular trauma determined by the number of treatment days and visual outcome. All subjects with vertical cup-to-disc ratio of the Optic nerve head, greater than 0.4 in either eye were excluded and referred to the nearest Teaching Hospital for further evaluation.

Ethical approval for the study was obtained from the ethical review board of Olabisi Onabanjo University Teaching Hospital, Sagamu. Informed verbal consent was obtained from the local heads of each community and informed written consent from each participant.

The study was conducted over a period of four months. And at each location, examinations were performed at the available Community hall. Snellen's visual acuity was assessed and the anterior and posterior segments were examined with a pen torch and direct ophthalmoscope respectively. Noncycloplegic refraction was performed using an automated refractor (SRJ-9900 CRT model, India) ${ }^{\mathrm{R}}$ and the average of two readings were recorded per eye. Keratometry was done with a keratometer (Bausch and Lomb Inc., Rochester, NY, USA) ${ }^{\mathrm{R}}$. An average of two readings were recorded for $\mathrm{k} 1$ / k2 in dioptres (D) for each eye and used for biometry [intraocular lens power calculation]. Axial length were measured using A-scan ultrasonography (Sueor SW-1000; China) ${ }^{R}$ in each eye. The posterior chamber intraocular lens power (PCIOL) was subsequently calculated (using the formula already incorporated into the A-scan) and was also recorded in Dioptres [D].

Data analysis: All data obtained were analysed using the SPSS software Version 21 (IBM Corp, New York, NY, USA).

Results: A total of 302 study participants were examined. There were 121 males (40\%) and 181 females (60\%). Due to media opacity [cataract], only $280(93 \%)$ had automated refractions performed. Table 1 presents the age distribution by gender for the total study population. The age range of participants were between 18 years and 93 years, with a mean of $43.59 \pm 17.96$ years.

\section{Visual acuity}

The presenting [unaided] visual acuity showed that $39(13 \%)$ had $6 / 5$ vision, 101(33\%) had 6/6, 60(20\%) had 6/9, 33(11\%)
$6 / 12$ and 11(4\%) had 6/18 vision. Overall, a total of 244 (81\%) study participants had equal to or better than $6 / 18$, $38(13 \%)$ had $<6 / 18$ to $6 / 60,11(4 \%)$ had $<6 / 60$ to $3 / 60$ while only $9(3 \%)$ were blind $(<3 / 60)$.

\section{Axial length}

The mean axial length [AL] was $23.31 \pm 0.91 \mathrm{~mm}$ and most of the study participants $[257,85 \%]$ had AL measurements of between $22 \mathrm{~mm}$ to $24.5 \mathrm{~mm}, 26(9 \%)$ were longer than $24.5 \mathrm{~mm}$ and only $19(6 \%)$ were shorter than $22.0 \mathrm{~mm}$. Males had longer statistically significant $\mathrm{AL}$ of $23.68 \pm 0.92 \mathrm{~mm}$ versus $23.05 \pm 0.81 \mathrm{~mm}$ for females $[p<0.001]$. Variation of AL with age showed a significant initial increase from $23.17 \pm 0.81 \mathrm{~mm}$ to $23.64 \pm 1.00 \mathrm{~mm}$ between the ages of 18 years and 40 years of age $[p<0.05]$ and this was followed by a progressive decrease after 40 years [Table 2]. AL also showed a significant inverse correlation with the refractive states [SER] of the participants $[p<0.05 ; \mathrm{r}=-0.26]$ as shown in Figure 1, but the regression equation ${ }^{15}[\mathrm{x}=9.51+(-0.39) \mathrm{y}]$ generated had a low coefficient of determination $\left[\mathrm{R}^{2}=0.07\right.$; Fig 1].

\section{Refraction}

Two hundred and thirteen [71\%] study participants had refractive error and the mean SER was

$0.46 \pm 1.34 \mathrm{D}$.

Astigmatism [40.7\%] was the commonest refractive state amongst the participants, followed by hyperopia [28.8\%], emmetropia [13.6\%] and myopia [8.6\%]. When these were converted to spherical equivalents, most participants 165 [55\%] were hyperopic and 48 [16\%] were myopic.

Variation of the refractive states with age showed a statistically significant mean myopic refractive state between ages 18 years and 20 years $[p<0.05]$, followed by a progressive increase in hypermetropia until after age 60yrs [Table 2].

\section{DISCUSSION}

The refractive state of the eye is determined by its overall biometric variables which includes, axial length, anterior chamber depth, lens thickness, posterior chamber depth and keratometric values but a knowledge of the average axial length especially in resource poor communities, where biometric facilities may be lacking can be helpful in the evaluation of refractive dilemmas.

There was a female preponderance [59\%] in this study population, which can be explained by the gender socio economic behaviour of males in this community who were mostly away at work during the day when the enumeration for the study was carried out. 
Data analysis for each eye showed that both the right eye [RE] and left eye [LE] had similar biometric measurements and spherical equivalent refraction [SER] as also documented by the Blue Mountain Eye Study[BMES] ${ }^{8}$.

There were 244 (81\%) study participants with no visual impairment [defined by visual acuity $<6 / 12$ ] which is comparable to previous studies by Onakpoyaet $\mathrm{al}^{18}$, and the National blindness and visual impairment survey ${ }^{19}$.

Although, most of the respondents in this study population did not have visual impairment, many [236, 78\%] had refractive errors, with hyperopia being more prevalent on consideration of spherical equivalence. These refraction values were however obtained from automated refraction which may not portray the actual clinically significant or subjective refractive errors.

Hyperopia was more common than myopia in this study population and this differs from previous studies which showed a reverse pattern ${ }^{20-22}$, although these previous studies were hospital-based, and could infer that myopes rather than hyperopes are more likely to access hospital optical services in Nigeria.

Refractive errors studies in other races have however shown that there is a higher prevalence of myopia in the Chinese than Caucasians and Afro-Americans ${ }^{23}$ as further documented by the Barbados eye study ${ }^{24}$ in an Afro-American population, where a higher prevalence of hyperopia [46.9\%] compared to myopia [21.9\%] in people of African descent was seen. Our study also revealed an increase in the rate of myopia and decrease in hyperopia after 60 years of age which was also documented by the Barbados eye study ${ }^{24}$.

This study also showed that $85 \%$ of our study participants had ALs between $22 \mathrm{~mm}$ and $24.5 \mathrm{~mm}$ which is the value used in most Regression formulae for IOL power calculation. The average AL of $23.31 \pm 0.91 \mathrm{~mm}$ obtained in this study was comparable to $23.57^{13}$ and $23.74 \mathrm{~mm}^{12}$ previously documented in South eastern and mid-western Nigeria respectively. This was also comparable to Caucasians $(23.44 \mathrm{~mm})^{8}$ and Chinese $(23.48 \mathrm{~mm})^{9}$ but shorter than values from India $(22.6 \mathrm{~mm})^{10}$ and Ivory Coast $(22.9 \mathrm{~mm})^{7}$ respectively.

Male participants had significantly longer AL $(0.62 \mathrm{~mm})$ than females as also documented in previous

Studies $^{8,12,25,26}$. This outcome is likely because males are generally physically bigger than females and hence have larger eyes as suggested by the Blue Mountain Eye Study ${ }^{8}$.

There was an increase in mean AL with age amongst the young adults [up to age 40 years] which was followed by a progressive decrease after age 40 years. This is noteworthy as previous studies only documented a decrease in AL with increasing age in older adults 40 years and above $e^{4,8,9}$. This initial increase in our study could mean that progressive AL elongation still continues far beyond the age of sixteen as previously documented ${ }^{5}$.

AL was found to be inversely related to the refractive state of the eye in this study but this showed a low coefficient of determination $\left[\mathrm{R}^{2}=0.07\right]$. This could be because the final refractive state of the eye is not only dependent on its AL but also the interaction between the individual's corneal curvature and its lens power ${ }^{6,27}$.

\section{CONCLUSION}

Ocular biometrics have become important in different diagnostic and operative procedures in Ophthalmology. Axial length was found to have a significant inverse relationship with the refractive state of the eye, but it was not a strong determinant of this refraction.

\section{ACKNOWLEDGEMENT}

We acknowledge the immense help received from the scholars whose articles are cited and included in the references of this manuscript.

The authors are also grateful to author/editors/publishers of all those articles, journals and books from where the literature for this article has been reviewed and discussed.

Source of funding: No external source of funding. Research was solely sponsored by the authors.

Conflict of interest: No conflict of interest.

\section{REFERENCES}

1. Scott RL. Optical correction of pediatricaphakia. Duanes Ophthalmology(CD-ROM) Philadelphia: Lippincott Williams and Wilkins;2006 Vol 1, Chap 45.

2. Lim KJ, Hung SM, Youn DH. Ocular dimensions with ageing in normal eyes. Korean J Ophthalmol 1992;6: 19-31.

3. Fledelius HC, Christensen AC. Reappraisal of the human ocular growth curve in foetal life, infancy and early childhood. Brit J Ophthalmol 1996; 80:918-921.

4. Senjeewa W, Paul JF, Davaatseren U, et al. Ocular biometry and refraction in Mongolian adults. Invest Ophthalmol and vis science 2004 ; 45:776-783.

5. Jurij RB, Frederick AJ. Embryology and anatomy of the orbit and lacrimal system. Duanes Ophthalmology (CD-ROM). Philadelphia: lipincott Williams and Wilkins 2006.

6. Badmus SA, Ajaiyeoba AI, Adegbehingbe BO, Onakpoya OH, Adeoye AO. Axial length/cornea radius of curvature ratio and the refractive status in an adult Nigerian population. Niger J Clin Pract 2017; 20: 1328-34.

7. Hideharu O, Yasushi I, Tomohiro S, Kanako O, Eiko O, Hitoshi T. Axial length changes in highly myopic eyes and influence of myopic macular complications in Japanese adults. PLOS One 2017; 12(7). 
8. Fotedar R, Wang JJ, Burlutsky G, Morgan IG et al. Distribution of axial length and ocular biometry measured using partial coherence laser interpherometry (IOL Master) in older white population [The Blue Mountain Eye Study]. Ophthalmol 2010; 117:417-423.

9. Hui C, Haotian L, Zhuoling L, Jingjing C, Weirong C. Distribution of axial length, anterior chamber depth and corneal curvature in an aged population in South China. BMC Ophthalmology 2016; 16:47. Doi 10.1186/s 12886-016-0221-5.

10. Nangia V, Jonas JB, Sinha A, et al. Ocular axial length and its associates in an adult population of central rural India. The central India eye and medical study. Ophthalmology 2010; 117:13601366.

11. Fanny A, Quattara A, Aka J, et al. Ocular biometric values of the black African patient and theoretical considerations of the role of these values in various pathologies. J Fr Ophth 2007; 30:69-72.

12. Iyamu E, Iyamu J, Obiakor CI. The role of axial length to corneal radius of curvature ratio in refractive state categorization in a Nigerian population. ISRN Ophthalmol 2011;13: 138941. Doi 10:5402/2011/138941.

13. Adio AO, Onua DO, Arowolo D. Ocular axial length and keratometry reading of normal eyes in Southern Nigeria. Nigerian Journal of Ophthalmology 2009;18[1]:12-14

14. Ogun State of Nigeria: Nigeria information and guide//www. nigeriagalleria.com. Nigeria/Ogun states. html. [Accessed 21/10/2018].

15. Araoye MO. Research methodology with statistics for health and social sciences. Ilorin, Nigeria: Nathadex Publishers;2003:pg 128.

16. Kirkwood BR, Sterne AC. Linear regression and correlation in essential medical statistics. $2^{\text {nd }}$ Edition, Blackwell publishing company. Oxford; 2003:87-93.

17. Forster PJ, Broadway DC, Havat S, et al. Refractive error axial length and anterior chamber depth of the eye in British adults. Br.J. Ophthalmol.2010;94:827-30.
18. Onakpoya $\mathrm{OH}$, Adeleye AO, Akinsola FB, Adegbeingbe BO. Prevalence of blindness and visual impairment in Atakumosa West Local Government area of South Western Nigeria. Tanzania Health Research Bulletin 2007; 9:126-131.

19. Kyari F, Gudlavaleti MV. Sivsubramaniam S, et al. Nigerian national blindness and study group. Prevalence of blindness and visual impairment: The Nigerian Nation Blindness and Visual impairment study. Invest Ophthalmol Vis Sci 2009;50 2033-9

20. Adefule-Ositelu AO. Refractive error in Lagos, Nigeria. Niger Med J 1995; 29(3): 101-103.

21. Adegbehingbe BO, Majekodunmi AA, Akinsola FB. Pattern of refractive errors at Obafemi Awolowo Teaching Hospital, Ile-Ife, Nigeria. Nigeria Journal of Ophthalmology 2003 Dec;11(2):7679.

22. Adeoti CO, Egbewale BE. Refractive errors in Mercyland specialist hospital Osogbo Western Nigeria. Nig Postgrad Med J 2008; 15:116-119.

23. Pan CW, Klein BE, Cotch MF, Shrager S, Klein R, Folsom A. et al. Racial variations in the prevalence of refractive error. The multi-ethnic study of Atherosclerosis. Am J. Ophthalmol. 2013; 155(6):1129-1138.

24. Suh-Yuh W, Nemesure B, Leske C. Refractive error in a black population. The Barbados eye study. Invest Ophthalmol and Vis Sci 1999; 40:2179-2184.

25. Tien YW, Paul J, Gordon JJ, Barbara EK, Steve KLS. The relationship between ocular dimensions and refraction with adult stature. Invest Ophthalmol Vis Sci 2001; 42:1237-1242.

26. Eysteisson T, Jonasson F, Arnasson A. Relationships between ocular dimensions and adult stature among participants in the Reykjavic eye study. Acta ophthalmol Scand 2005; 83:734-738

27. Brown NP, Koretz JF, Bron AJ. The development and maintenance of emmetropia. Eye. 2003; 44:1479-1485.

Table 1: Age and sex distribution of the study population

\begin{tabular}{lccc} 
Age[years] & Frequency & {$[\%]$} & Total \\
$\leq 20$ & Male & Female & $42[13.9]$ \\
$21-30$ & $12[9.9]$ & $30[16.6]$ & $50[16.6]$ \\
$31-40$ & $16[13.2]$ & $34[18.8]$ & $37[12.3]$ \\
$41-50$ & $18[14.9]$ & $19[10.5]$ & $68[22.5]$ \\
$51-60$ & $28[23.1]$ & $40[22.1]$ & $52[17.2]$ \\
$61-70$ & $19[15.7]$ & $33[18.2]$ & $34[11.3]$ \\
$\geq 71$ & $17[14.0]$ & $17[9.4]$ & $19[6.3]$ \\
Total & $11[9.1]$ & $8[4.4]$ & $302[100]$ \\
Mean & $121[100]$ & $181[100]$ & $43.59 \pm 17.96$ \\
Chi Square=5.19 & $46.06 \pm 18.00$ & $41.93 \pm 17.79$ & \\
\hline
\end{tabular}

$\%=$ Percentage, $\leq=$ less than or equal to, $\geq=$ greater than or equal to, $\mathrm{df}=$ degree of freedom, $\mathrm{p}=$ level of significance at $\mathrm{p}<0.05$. 
Table 2: Variation of ocular axial length and SER per decade of age among the participants.

\begin{tabular}{lccc} 
Age $[\mathrm{yrs}]$ & Frequency & AL $[\mathrm{mm}]$ & SER $\{\mathrm{D}\}$ \\
$\leq 20$ & 42 & $23.17 \pm 0.81$ & $-0.13 \pm 1.12[42]$ \\
$21-30$ & 50 & $23.47 \pm 0.85$ & $0.28 \pm 0.85[50]$ \\
$31-40$ & 37 & $23.64 \pm 1.00$ & $0.29 \pm 1.12[37]$ \\
$41-50$ & 68 & $23.50 \pm 0.75$ & $0.39 \pm 1.25[66]$ \\
$51-60$ & 52 & $23.05 \pm 0.85$ & $1.23 \pm 1.39[49]$ \\
$61-70$ & 34 & $23.00 \pm 0.98$ & $0.93 \pm 1.51[28]$ \\
$\geq 71$ & 19 & $22.89 \pm 0.66$ & $0.47 \pm 2.00[16]$ \\
P Value & & 0.001 & 0.000 \\
\hline
\end{tabular}

$\mathrm{AL}=$ axial length, $\mathrm{SER}=$ spherical equivalent, [] = figures within the bracket indicates the frequency distribution of SER.

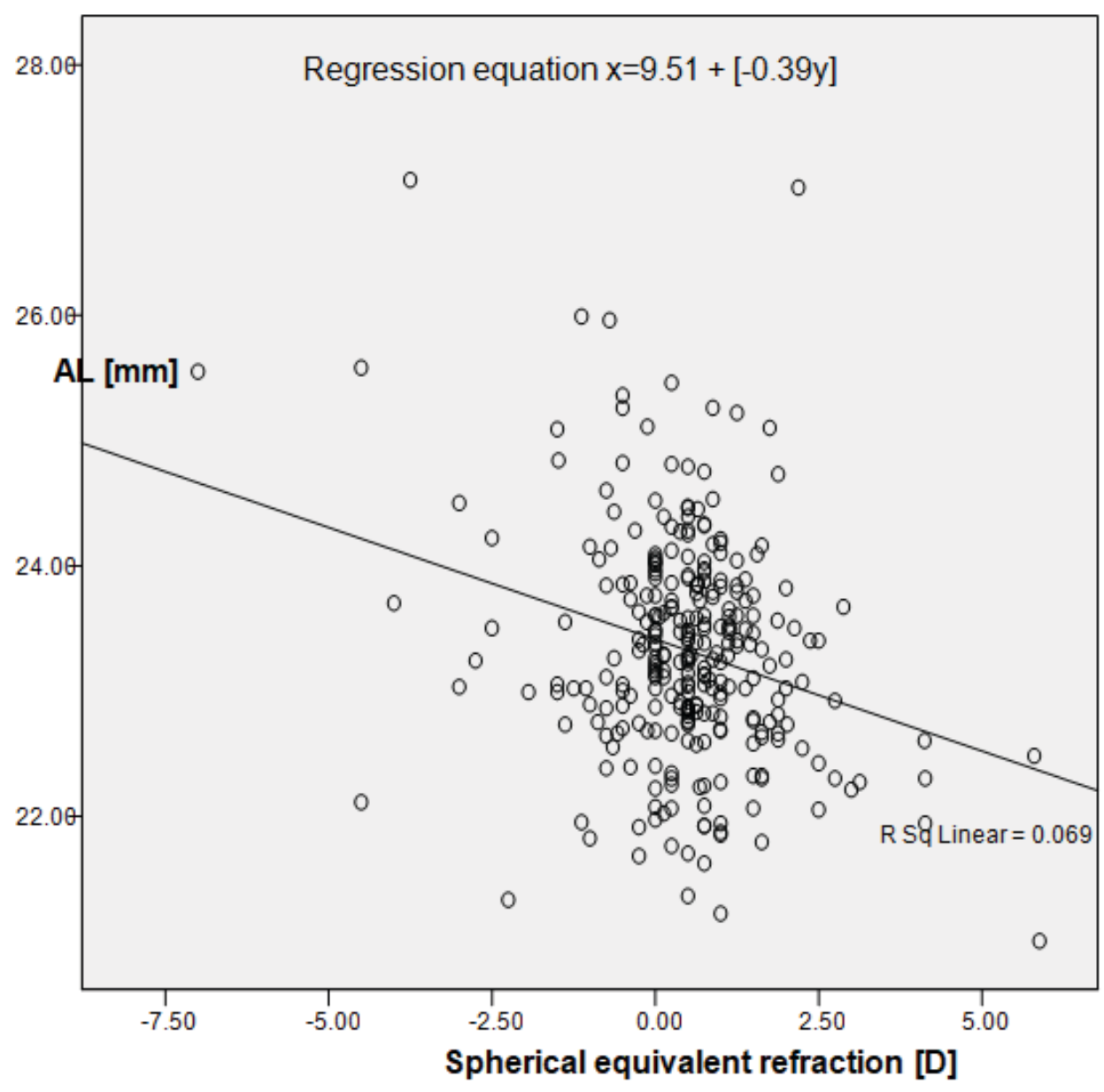

$\mathrm{AL}=$ Axial length, $\mathrm{D}=$ Dioptres.

Figure 1: Scattered plot of axial length and refraction for the study population. 